\title{
The immediate extinction deficit occurs in a nonemotional learning paradigm
}

\author{
Christian J. Merz and Oliver T. Wolf \\ Department of Cognitive Psychology, Faculty of Psychology, Institute of Cognitive Neuroscience, Ruhr University Bochum, \\ 44780 Bochum, Germany
}

\begin{abstract}
The immediate extinction deficit describes a higher return of fear when extinction takes place immediately after fear acquisition compared to a delayed extinction design. One explanation for this phenomenon encompasses the remaining emotional arousal evoked by fear acquisition to be still present during immediate, but not delayed extinction. In the present study, the predictive learning task, a learning task not involving arousal or stress, was used testing the hypothesis that no immediate extinction deficit should occur in this neutral task. Twenty-six participants underwent an immediate extinction procedure and were tested in a recall session $24 \mathrm{~h}$ later. For the delayed extinction group $(n=26)$, acquisition, extinction, and recall were realized $24 \mathrm{~h}$ apart from each other. Recall performance of a third group $(n=26)$ was tested $48 \mathrm{~h}$ after the immediate extinction procedure. The immediate extinction deficit was indeed observed for a stimulus not subject to a contextual change from acquisition to extinction, but not for other stimuli involving contextual changes or no extinction control stimuli. Even in a neutral learning task and without emotional arousal, the immediate extinction deficit could be detected but was restricted to the specific contextual embedding of stimuli. Thus, contextual processing appears to differentially modulate the emergence of the immediate extinction deficit.
\end{abstract}

Contextual changes as well as elapsing time comprise powerful tools for the investigation and closer understanding of learning and memory processes (e.g., Rescorla 2004; Maren et al. 2013). One prominent example for the impact of contextual changes encompasses the renewal effect (Bouton 2004), which outlines extinguished responses to reappear context-dependently: for instance, after acquisition of conditioned responses in context $A$ and extinction in context $\mathrm{B}$, conditioned responding is typically higher in context $\mathrm{A}$ compared to context $\mathrm{B}$ during recall $(\mathrm{AB}(\mathrm{AB})$ design; Vervliet et al. 2013a,b). Not only spatial contexts, but also social, cultural, cognitive, interoceptive, and temporal contexts can serve as powerful contexts (Maren et al. 2013). In particular, elapsing time or changes in time were also considered as (new temporal) contexts (Bouton 2002, 2004).

Time-dependent changes of extinction processes have been described in the immediate extinction deficit: extinguished responses recover more easily and stronger when extinction immediately follows acquisition in contrast to extinction taking place after a delay (delayed extinction; usually $24 \mathrm{~h}$ after acquisition; Maren 2014). This deficit has been shown in particular using fear conditioning paradigms in rodents (Maren and Chang 2006; Woods and Bouton 2008; Chang and Maren 2009, 2011; Chang et al. 2010; Kim et al. 2010; MacPherson et al. 2013; Stafford et al. 2013; Hollis et al. 2016; Giustino et al. 2017; Singh et al. 2018; but see Myers et al. 2006) and humans (Alvarez et al. 2007; Schiller et al. 2008; Huff et al. 2009; Merz et al. 2016; but see Norrholm et al. 2008; Golkar and Öhman 2012). Presumably, emotional and stress responses evoked by the fear acquisition procedure (due to the accompanying application of aversive shocks) are still present during subsequent immediate extinction, but not during delayed extinction. This arousal state is assumed to compromise the encoding of the extinction memory trace emerging during immediate extinction by impairing functioning of the infralimbic part of the prefrontal cortex via high noradrenergic and/or glucocorticoid signaling (Holmes and Wellman 2009;

\section{Corresponding author: christian.j.merz@rub.de}

Article is online at http://www.learnmem.org/cgi/doi/10.1101/lm.048223.118.
Maren 2014; Merz et al. 2014; Giustino and Maren 2015; Maren and Holmes 2016; Giustino et al. 2017). Eventually, a higher return of fear conditioned responses should occur after immediate extinction (compromised by preceding arousal and stress) compared to delayed extinction (Maren 2014; Maren and Holmes 2016). Thus, a task not evoking arousal or stress should not lead to the immediate extinction deficit; a hypothesis, which was tested in this study using a neutral, predictive learning task similar to that previously used by Üngör and Lachnit $(2006,2008)$, which is not supposed to lead to any emotional or stress responses (cf. Kinner et al. 2016).

An immediate extinction group (acquisition and immediate extinction; $24 \mathrm{~h}$ later: recall) was contrasted to a delayed extinction group (acquisition, extinction, and recall each $24 \mathrm{~h}$ apart from each other). To account for the different delay between acquisition and recall in both groups, which might also be involved in the observed effects (cf. Kim and Richardson 2009; Johnson et al. 2010), a further immediate extinction group was included with the same acquisition-recall delay as the delayed extinction group (i.e., acquisition and immediate extinction; $48 \mathrm{~h}$ later: recall). If the immediate extinction deficit is caused by the arousal induced by fear acquisition (cf. Maren 2014; Maren and Holmes 2016), no immediate extinction deficit should occur in the neutral, predictive learning task used in the current study. If the immediate extinction deficit is however also present in this task without an emotional component, a more fundamental learning mechanism underlying this effect needs to be considered.

\section{Results}

Blood pressure

Systolic blood pressure decreased from pre- to post-acquisition (pre: $M \pm S D=119.7 \pm 15.4$; post: $M \pm S D=116.7 \pm 14.7$; main effect

(C) 2019 Merz and Wolf This article is distributed exclusively by Cold Spring Harbor Laboratory Press for the first 12 months after the full-issue publication date (see http://learnmem.cshlp.org/site/misc/terms.xhtml). After 12 months, it is available under a Creative Commons License (Attribution-NonCommercial 4.0 International), as described at http://creativecommons.org/licenses/by-nc/4.0/. 
time: $F_{(1,72)}=8.12 ; P=0.006$; all other $\left.P \mathrm{~s}>0.21\right)$, whereas no effect was found for diastolic blood pressure (all Ps $>0.45$ ). Systolic as well as diastolic blood pressure did not change from pre- to postextinction (all Ps $>0.084$ ). For recall, systolic blood pressure went down from pre- to post-recall (pre: $M \pm S D=122.5 \pm 16.0$; post: $M \pm \mathrm{SD}=114.5 \pm 12.9$; main effect time: $F_{(1,72)}=44.89 ; P<0.001$; all other $P \mathrm{~s}>0.27)$, but no effect emerged for diastolic blood pressure (all $P s>0.16$ ). Taken together, blood pressure data indicate no activation of the sympathetic nervous system related to the different experimental phases of the predictive learning task.

\section{Acquisition}

Over the course of acquisition, participants learned to predict stomach trouble to be associated with certain stimuli $(\mathrm{a}+, \mathrm{c}+, \mathrm{e}+)$, but not with other stimuli (b-, d-, $\mathrm{f}-$; stimulus $\times$ block interaction: $F_{(2.1,140.0)}=113.50 ; P<0.001 ;$ main effect block: $F_{(2.0,132.6)}=11.10$; $P<0.001$; main effect stimulus: $F_{(1,68)}=820.20 ; P<0.001$; cf. Fig. 1). No further main or interaction effects emerged (all other Ps $>$ 0.067).

\section{Extinction}

Over the course of extinction, participants learned to predict that stimuli previously coupled with stomach trouble $(\mathrm{a}-, \mathrm{c}-)$ were no longer associated with stomach trouble compared to stimuli still not coupled with stomach trouble $(\mathrm{b}-, \mathrm{d}-;$ stimulus $\times$ block interaction: $F_{(2.1,149.5)}=29.28 ; P<0.001$; main effect block: $F_{(2.2,158.4)}=$ $118.45 ; P<0.001$; main effect stimulus: $F_{(1,72)}=31.12 ; P<0.001$; cf. Fig. 1).

In addition, contextual change (realized for stimuli $a-$ and $b-$, but not for stimuli $\mathrm{c}-$ and $\mathrm{d}-$ ) modulated this effect (stimulus $\times$ block $\times$ context interaction: $\left.F_{(2.0,141.1)}=6.49 ; P=0.002\right)$ : post-hoc tests indicated that this interaction was driven by stimuli $\mathrm{b}-$ and d- (context $\times$ block interaction: $F_{(2.0,141.9)}=6.62 ; P=0.002$; for stimuli a- and c-: context $\times$ block interaction: $P>0.18)$. In particular, participants predicted more stomach trouble toward $b-$ (undergoing a contextual change) compared to d- (not undergoing a contextual change) only during the first block of extinction
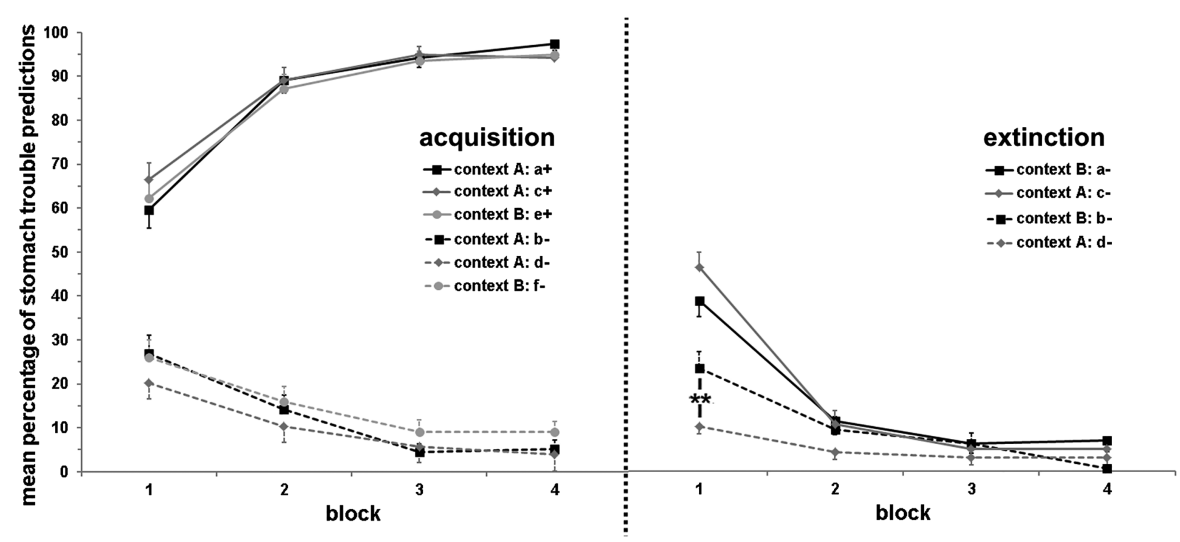

Figure 1. Mean $( \pm S E M)$ percentage of stomach trouble predictions to critical stimuli across four blocks (including two trials each) during acquisition (left) and extinction (right) across all three experimental groups (no significant group differences emerged). Stimuli were presented in context A or B and were associated with stomach trouble $(+)$ or not $(-)$ during acquisition; during extinction, all critical stimuli were no longer paired with stomach trouble (-). Stimulus a+ underwent a change in contingency and context, stimulus $c+$ was subject to a change in contingency, and stimulus e+ was not presented during extinction. The control stimulus $b$ - underwent a change in context, stimulus $d$ - did not undergo any change, and stimulus $\mathrm{f}-$ was not shown during extinction. Successful learning of the contingencies of all stimuli was observed during acquisition. During extinction, the contingency and outcome change was also successfully learned over time. In addition, participants predicted more stomach trouble toward b-compared to d-during the first block of extinction. $\left({ }^{*}\right) P<0.01$. (main effect stimulus: $F_{(1,72)}=9.22 ; P=0.003$ ), but not in later blocks (all $P$ s $>0.12$; cf. Fig. 1). No further main or interaction effects emerged, in particular no significant group differences were ob-

\section{Recall}

During recall, a contextual modulation was found for stimuli c and which did not undergo a contextual change from acquisi$P<0.001$; main effect context: $F_{(1,71)}=12.29 ; P=0.001$; main effect stimulus d (main effect context: $F_{(1,71)}=4.01 ; P=0.049$; not significorter adjustment for two post-hoc tests), but for stimulus c, for (acquisition and extinction context) compared to context B (new text; main effect context: $F_{(1,71)}=18.49 ; P<0.001$; cf. Fig. 2$)$. general stomach trouble predictions for stimuli $\mathrm{c}$ and $\mathrm{d}$, irrespective of the context (stimulus $\times$ group interaction: $F_{(2,71)}=4.06 ; P=$ 0.021): Significant group differences were observed for stimulus $c$ 0.57). Post-hoc tests indicated that the immediate extinction (early recall) group gave more stomach trouble predictions for stimulus c mmediate extinction (late recall) group was situated in the middle Ps > 0.08; cf. Fig. 2). Additional planned tests also confirmed a extinction (early recall) group (stimulus $\times$ context interaction: $\left.F_{(1,24)}=8.44 ; P=0.008\right)$ and the immediate extinction (late recall) but not in the delayed extinction group $(P>0.14)$. Both immediate groups indicated more stomach trouble for stimulus $\mathrm{c}$ in context $\mathrm{A}$ to B (both $P$ s $<0.014$ ), but not in context B (both Ps > 0.068 ); this pattern was not observed in the delayed extinction For stimuli a and $\mathrm{b}$, a renewal effect was revealed (stimulus $\times$ context interaction: $F_{(1,72)}=23.00 ; P<0.001$; main effect context: $F_{(1,72)}=11.10 ; P<0.001$; main effect stimulus: $\left.F_{(1,72)}=84.53 ; P<0.001\right)$, whereas context did not matter for $\mathrm{b}(P>0.29)$, higher stomach trouble predictions were given for stimulus a in context A (acquisition context) compared to context B (extinction context; main effect context: $F_{(1,72)}=19.95 ; P<0.001$; cf. Fig. 3$)$.

For stimuli e and f (serving as no extinction control stimuli), only higher stomach trouble predictions for e in comparison to $\mathrm{f}$ were observed during recall (main effect stimulus: $F_{(1,72)}=93.17 ; P<$ 0.001; cf. Fig. 4).

No further significant main or interaction effects other than reported were found for the recall phase.

\section{Discussion}

The present study investigated the immediate extinction deficit in humans in a nonemotional task involving stimulus associations undergoing contextual and/or contingency change during extinction. Three experimental groups were created with differences in the interval between 


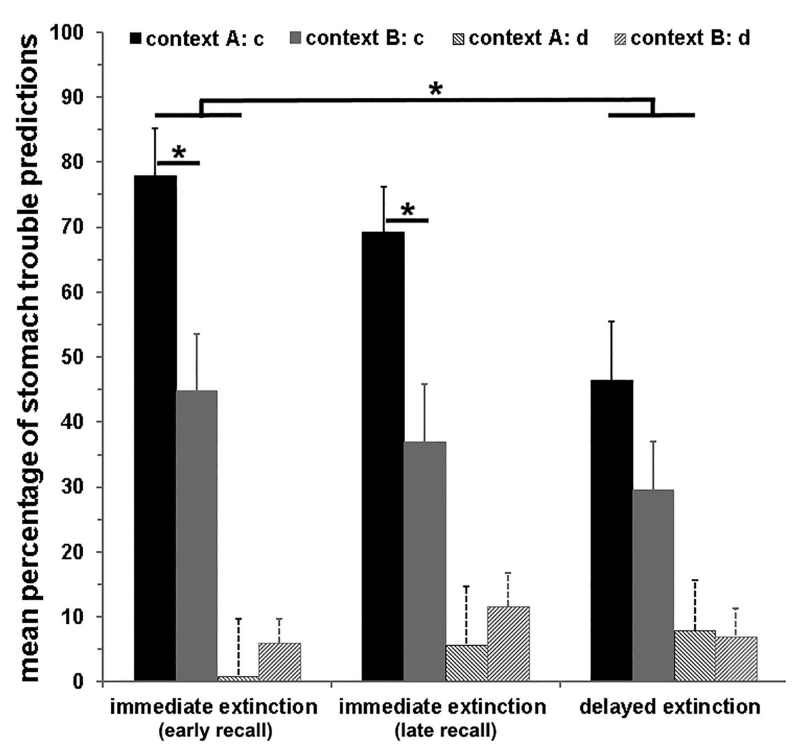

Figure 2. Mean $( \pm S E M)$ percentage of stomach trouble predictions during recall in contexts $A$ and $B$, presented separately for the three groups (immediate extinction [early recall]; immediate extinction [late recall]; delayed extinction) and stimuli $c$ and $d$ not undergoing a context change during extinction. During acquisition, stimulus $c$ was associated with stomach trouble, while stimulus d was not paired with stomach trouble. During extinction, both stimuli were no longer paired with stomach trouble. Significant group differences were observed for stimulus c, for which participants in the immediate (early recall) indicated more stomach trouble predictions compared to the delayed extinction group, irrespective of the context. $\left({ }^{*}\right) P<0.05$. Additionally, both immediate extinction groups gave higher stomach trouble predictions toward stimulus C in context A compared to context B. $\left(^{*}\right) P<0.05$, whereas this pattern was not found for the delayed extinction group.

acquisition and extinction as well as between acquisition and recall. Indeed, the immediate extinction deficit emerged, which was however restricted to the stimulus not subject to a contextual change during extinction (stimulus c). Thus, our current findings are in large agreement with, but also extend beyond previous literature on the immediate extinction deficit in rodents (Maren and Chang 2006; Woods and Bouton 2008; Chang and Maren 2009, 2011; Chang et al. 2010; Kim et al. 2010; MacPherson et al. 2013; Stafford et al. 2013; Hollis et al. 2016; Giustino et al. 2017; Singh et al. 2018; but see Myers et al. 2006) and humans (Alvarez et al. 2007; Schiller et al. 2008; Huff et al. 2009; Merz et al. 2016; but see Norrholm et al. 2008; Golkar and Öhman 2012).

For fear (and also appetitive) conditioning, it was proposed that the remaining arousal or stress from the acquisition phase impairs immediate extinction learning via high noradrenergic and/or glucocorticoid signals inhibiting prefrontal functioning (cf. Arnsten 2009) required for encoding and consolidation of extinction memories (Holmes and Wellman 2009; Maren 2014; Merz et al. 2014; Giustino and Maren 2015; Maren and Holmes 2016; Giustino et al. 2017). For example, administration of the stress hormone cortisol impaired extinction learning when given before immediate extinction (Merz et al. 2014), but enhanced extinction learning when applied before delayed extinction in humans (Merz et al. 2018). However, the current findings do not support this arousal/stress hypothesis, since the predictive learning task does not include any emotional component and also did not increase activity of the sympathetic nervous system (measured with blood pressure), thus, no arousal or stress was initiated. Nevertheless, we observed the immediate extinction deficit for stimulus c (undergoing a change in contingency), but not for stim- ulus a (undergoing a change in contingency and outcome) or the no extinction control stimulus e. On the one hand, the failure to detect the immediate extinction deficit for stimulus a $(\mathrm{AB}(\mathrm{AB})$ design) might be related to masking effects due to spontaneous recovery effects in the delayed extinction group. On the other hand, arousal/stress might be necessary for the immediate extinction deficit to occur for $\mathrm{AB}(\mathrm{AB})$ designs, but not for $\mathrm{AA}(\mathrm{AB})$ designs, in which no contextual change is realized between acquisition and extinction.

In $\mathrm{AA}(\mathrm{AB})$ designs, the two experiences (acquisition and immediate versus delayed extinction) could be perceived as one unique experience related to the first association, which was learned (association with stomach trouble). Thus, during recall, the chance of interference of these two experiences with each other might be higher in $\mathrm{AA}(\mathrm{AB})$ designs compared to $\mathrm{AB}(\mathrm{AB})$ designs (cf. temporal weighting model; Devenport 1998), independent of the timing of extinction relative to acquisition. Eventually, the immediate extinction deficit should less likely emerge in $\mathrm{AA}(\mathrm{AB})$ designs. Indeed, prior experiments reporting the immediate extinction deficit usually applied $\mathrm{AB}(\mathrm{AB})$ fear conditioning designs (Maren and Chang 2006, experiment 4; Alvarez et al. 2007; Woods and Bouton 2008; Chang and Maren 2009, 2011; Huff et al. 2009; Chang et al. 2010; Kim et al. 2010; MacPherson et al. 2013; Hollis et al. 2016; Giustino et al. 2017), but not so often $\mathrm{AA}(\mathrm{AB})$ designs (Maren and Chang 2006, experiments 1-3, 5; Huff et al. 2009), for which the immediate extinction deficit has not been found reliably (Myers et al. 2006; Norrholm et al. 2008; Schiller et al. 2008; Kim and Richardson 2009; Archbold et al. 2010; Golkar and Öhman 2012). On the contrary, some of these studies even observed higher conditioned responding in the delayed compared to the immediate extinction group (Myers et al. 2006; Norrholm et al. 2008; Golkar and Öhman 2012) leading to

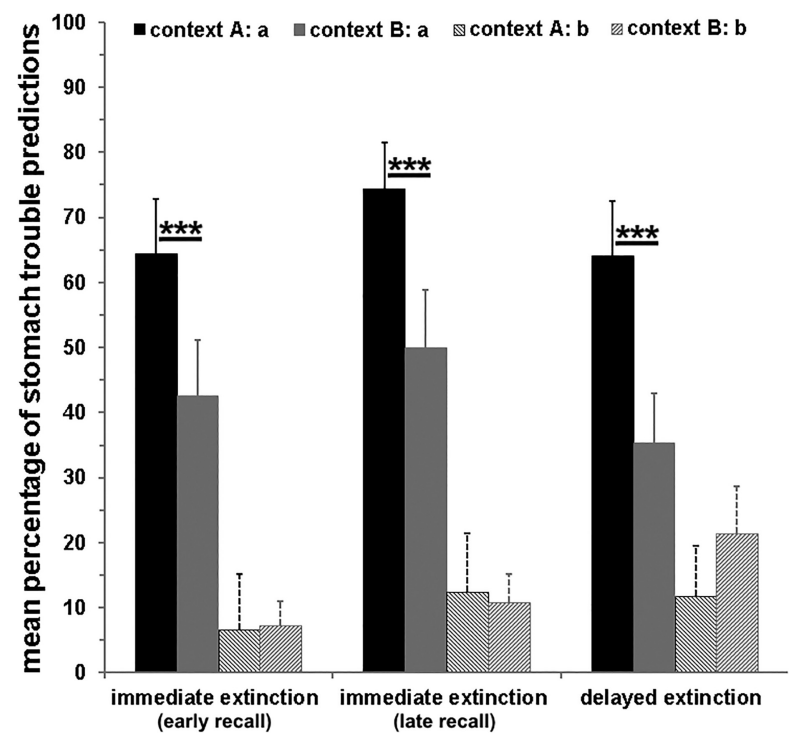

Figure 3. Mean $( \pm S E M)$ percentage of stomach trouble predictions during recall in contexts $A$ and $B$, presented separately for the three groups (immediate extinction [early recall]; immediate extinction [late recall]; delayed extinction) and stimuli a and $b$ undergoing a context change during extinction. During acquisition, stimulus a was associated with stomach trouble, while stimulus b was not paired with stomach trouble. During extinction, both stimuli were no longer paired with stomach trouble. A renewal effect emerged indicated by higher stomach trouble predictions toward stimulus a in context A compared to context B. $\left.{ }^{* * *}\right) P<0.001$. No group differences occurred for stimuli $a$ and $b$ indicating that stimuli undergoing a context change during extinction were not subject to the immediate extinction deficit. 


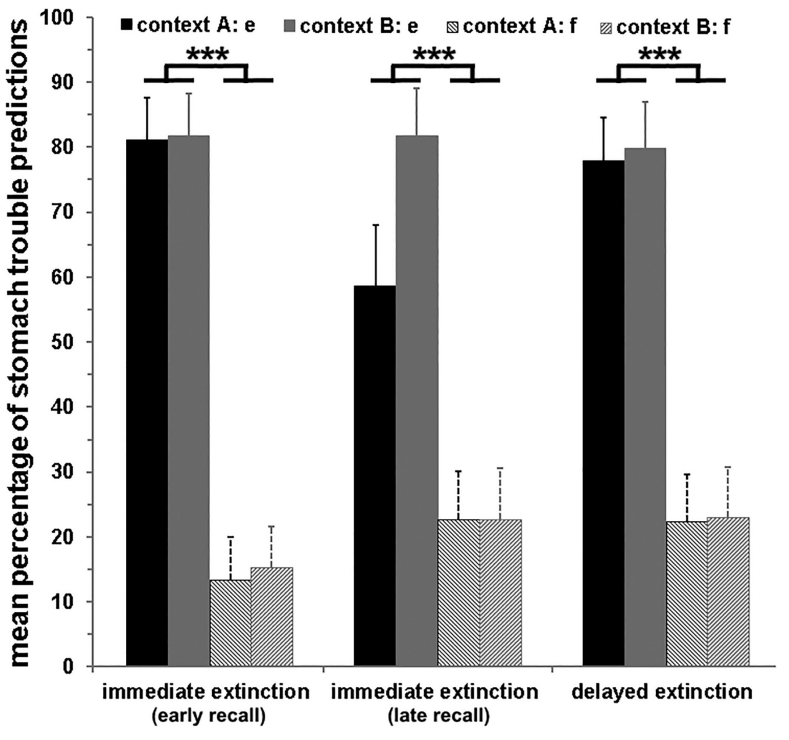

Figure 4. Mean $( \pm S E M)$ percentage of stomach trouble predictions during recall in contexts $A$ and $B$, presented separately for the three groups (immediate extinction [early recall]; immediate extinction [late recall]; delayed extinction) and stimuli e and $\mathrm{f}$, which were not presented during extinction. During acquisition, stimulus e was associated with stomach trouble, while stimulus $f$ was not paired with stomach trouble. Higher stomach trouble predictions were given toward stimulus e compared to stimulus $f$, irrespective of the context $\left({ }^{\star * *}\right) P<0.001$. No group differences occurred for stimuli e and $f$.

the assumption that immediate extinction might erase the original fear memory trace. This discrepancy might be resolved by taking context into account: future studies should directly compare immediate and delayed extinction in $\mathrm{AA}(\mathrm{AB})$ and $\mathrm{AB}(\mathrm{AB})$ designs (cf. Huff et al. 2009) to have a closer look at contextual influences.

The contextual change during extinction might serve as a strong cue that a new association might be established in contrast to a situation with no contextual change. In addition to the critical role of the infralimbic cortex (Chang et al. 2010; Kim et al. 2010; Singh et al. 2018) and the basolateral amygdala (Giustino et al. 2017) for the immediate extinction deficit, contextual processing of critical stimuli in the hippocampus (Maren et al. 2013) could thus represent a reasonable mechanism for the reported differential effects to be characterized in future efforts. Similarly, the interrelationship between stimuli and contexts could be explored further to gain more insights into the underlying mechanisms. For example, cue competition effects such as overshadowing (Pavlov 1927; Kaufman and Bolles 1981) might play a role in the occurrence of the immediate extinction deficit. Since stimuli and contexts were both paired with a specific outcome during acquisition and extinction, but not presented separately from each other, possible overshadowing effects cannot be tested in the current design. In the future, overshadowing could be investigated to test if the stimuli or the contexts (or both) are associated with the immediate extinction deficit.

One strength of the present study consists in the addition of a further immediate extinction group undergoing the recall test $48 \mathrm{~h}$ after acquisition and immediate extinction (in contrast to the standard immediate extinction group tested $24 \mathrm{~h}$ later and comparable to the acquisition-recall delay in the delayed extinction group). This approach allowed us to test if the delay between acquisition and recall plays an additional role in the immediate extinction deficit. The overall analyses assumed the acquisition-recall interval to be relevant since only the immediate extinction (early recall) group displayed higher stomach trouble predictions toward stimulus c compared to the delayed extinction group, whereas no significant group difference emerged for the immediate extinction (late recall) group. But if the acquisition-recall interval was indeed important, recall data of the immediate extinction (early recall) group should be significantly different from the immediate extinction (late recall) group, which was not the case. Furthermore, the relevance of the acquisition-recall interval seems limited, because both immediate extinction groups displayed a context-dependent reemergence of stomach trouble predictions for stimulus c, whereas this effect was absent in the delayed extinction group as reported before (Üngör and Lachnit 2008). Thus, the current results cannot fully answer this question, but appear to be in contrast with the assumption of a strong involvement of the acquisition-recall interval in the occurrence of the immediate extinction deficit. Nevertheless, future studies should more closely investigate the timing between acquisition and recall, in particular in fear conditioning designs.

Intriguingly during early extinction, contextual change led to higher stomach trouble predictions for the stimulus never associated with stomach trouble (b-) compared to the control stimulus with no contextual change (d-). A comparable contextual modulation has been observed before in the predictive learning task (Kinner et al. 2016) and during immediate fear extinction, but more related to skin conductance responses regarding the stimulus previously coupled with the unconditioned stimulus (Sjouwerman et al. 2015). These findings could be explained by the fact that participants might assume the context change to come along with a contingency change as well. The rodent literature also concurs with these results, at least regarding instrumental conditioning, but not fear conditioning procedures (Bouton and Todd 2014). Likewise, others could not find an effect of contextual change on fear extinction in humans (Effting and Kindt 2007; Dibbets et al. 2008; Neumann and Kitlertsirivatana 2010; Bandarian Balooch and Neumann 2011). Thus, future research should ideally identify relevant conditions (instrumental versus classical conditioning; rodents versus humans, etc.) for the reported context switch to occur.

Indeed, the predictive learning task represents a neutral task not involving emotional responses suitable to test the current hypothesis. However, it does not include a physical unconditioned stimulus (such as an electrical stimulation) typically used in fear conditioning experiments, for which the immediate extinction deficit has been observed as delineated above. Future studies could address this issue by including a nonaversive stimulus such as a vibrotactile stimulation (e.g., Hamm and Vaitl 1996).

In conclusion, the immediate extinction deficit emerged in the present study even in the absence of fear acquisition-related arousal or stress. However, it was restricted to a stimulus not undergoing a contextual change during extinction pointing to the importance of contextual embedding of critical stimuli for the immediate extinction deficit to occur. After a context change from acquisition to extinction, the immediate extinction deficit was not found, providing indirect evidence for the assumption that the remaining arousal/stress from the acquisition phase in fear conditioning studies might be involved in the emergence of the immediate extinction deficit (Maren 2014). Future studies should disentangle boundary conditions for the immediate extinction deficit to occur, the present study strongly argues for the importance of contextual cues.

\section{Materials and Methods}

\section{Participants}

In total, 39 men and 39 women (aged 19-37; mean age \pm SD: $25.2 \pm$ $4.0 \mathrm{yr}$ ) were recruited via email announcements, flyers at the 
university or personal address. Most of them were students, five participants were self-employed or working at the university. In a telephone interview, the following exclusion criteria were checked: age outside the range of 18-40 yr, chronic or acute illnesses, history of psychiatric or neurological treatment, drug use or regular intake of medicine, and current pregnancy. All participants had normal or corrected-to-normal vision. In addition, participants were instructed to refrain from consumption of food $1 \mathrm{~h}$ prior to each experimental day.

Participants received an explanation of the procedure, signed the informed consent form and filled out questionnaires regarding demographic data. After finishing the predictive learning task (spread over 2 or $3 \mathrm{~d}$; cf. section "Predictive learning task"), they were reimbursed with $20 €$ for their participation and received additional information regarding the aim of the study. All procedures were in line with the Declaration of Helsinki and were approved by the local ethics committee.

\section{Predictive learning task}

Participants were instructed to imagine being a doctor of a patient who occasionally suffers from stomach trouble after having meals in his two favorite restaurants. The experiment encompassed an acquisition phase, an extinction phase, and a recall test. Table 1 depicts the training schedule of the experiment.

During the acquisition phase, stimuli a+ and $\mathrm{c}+$ in context $\mathrm{A}$ and stimulus e+ in context B were each paired with the outcome of stomach trouble $(+)$, while no stomach trouble $(-)$ followed each of the stimuli $b-$ and $d-$ in context $A$ and stimulus $\mathrm{f}-$ in context B. At the start of each trial, a picture of one of eight food stimuli (vegetables and fruits, e.g., cucumber or cherries) was shown on a computer screen for $3 \mathrm{sec}$ in one of two contexts (differing in the color of the frame and the restaurant name, "the bell" versus "the dragon," surrounding the respective food stimulus). Within a response time window of $2.5 \mathrm{sec}$, participants had to predict whether their patient will or will not experience stomach trouble after having eaten this food. On the bottom of the screen, the question "Do you expect that the patient will experience stomach trouble" was superimposed with the possible answer options "yes" and "no," which could be chosen by pressing the corresponding button on the keyboard. Feedback with the correct answer was displayed afterwards for another $2.5 \mathrm{sec}$ either in green color for correct predictions or in red color for wrong predictions or missing responses. In the inter-trial interval, a white fixation cross was shown on a black screen for $1 \mathrm{sec}$.

During the extinction phase, four of the stimuli presented during the acquisition phase were shown again, but differed concerning contextual embedding or outcome (see Table 1). Particularly, stimuli a and c were no longer associated with stomach trouble during the extinction phase. The change in outcome contingency took place in the original context A for stimulus $\mathrm{C}$ or was accompanied by a contextual change to context $B$ in case of stimulus $\mathrm{a}$. In contrast, stimuli $\mathrm{b}$ and $\mathrm{d}$ continued to be followed by no stomach trouble during the extinction phase, with a shift to context $B$ related to stimulus $b$, whereas no context shift occurred for stimulus d. Stimuli e and $f$ served as no extinction control stimuli and were not presented during extinction.

For acquisition and extinction respectively, in total eight stimuli were presented eight times each (total duration of each phase: about $10 \mathrm{~min}$ ). Additional stimuli g to 1 were trained in order to make overall learning more difficult and to balance stomach trouble outcomes within each context (Hamacher-Dang et al. 2013a,b; Lissek et al. 2013; Meir Drexler et al. 2017; cf. Table 1). Trial order was randomized within four blocks, whereas each block contained two presentations of all stimuli of the respective learning phase. Presentation order was randomized within each block.

During the recall phase, memory for six stimulus-outcome associations ( $a, b, c, d, e$, and $\mathrm{f}$ ) was tested in both contexts, this time without feedback (total duration: about $7 \mathrm{~min}$ ). Each stimulus occurred four times in each context (in sum 48 trials, cf. Table 1). The resulting 12 stimulus-context combinations were randomized in two blocks containing two stimulus presentations in each context. In addition, stimulus and context allocation was also randomized for each participant, but matched between the three experimental groups (cf. section Allocation to the experimental groups).

\section{Allocation to the experimental groups}

Men and women were equally and randomly assigned to one of three different groups (each group comprises 13 men and 13 women, respectively) differing in the time between acquisition, extinction, and recall (cf. Table 2): The immediate extinction group (early recall) underwent acquisition and immediate extinction on $1 \mathrm{~d}$, recall took place $24 \pm 2 \mathrm{~h}$ later. For the immediate extinction group (late recall), acquisition and immediate extinction was also scheduled on $1 \mathrm{~d}$, but recall was tested $48 \pm 2 \mathrm{~h}$ later. For the delayed extinction group, all experimental phases took place on separate days: after acquisition on a first day, participants underwent extinction $24 \pm 2 \mathrm{~h}$ later and recall was scheduled $24 \pm 2 \mathrm{~h}$ after extinction.

\section{Blood pressure}

Systolic and diastolic blood pressure was measured as indicators of activation of the sympathetic nervous system. The cuff of the Dinamap vital signs monitor (Critikon, Tampa, FL) was placed on participants' left upper arm. Measurements were taken at the beginning and the end of each experimental day, i.e., for the immediate extinction groups before and after acquisition (corresponding to before extinction) as well as after extinction on day 1 and before and after recall. For the delayed extinction group, blood pressure was measured before and after acquisition, extinction, and recall, respectively.

Table 1. Design of the predictive learning task

\begin{tabular}{|c|c|c|c|}
\hline & Acquisition & Extinction & Recall \\
\hline \multicolumn{4}{|l|}{ (a) } \\
\hline Context A & $\mathbf{a}+, \mathbf{b}-, \mathbf{c}+, \mathbf{d}-$ & $\mathbf{c}-, \mathbf{d}-, \mathrm{i}+, \mathrm{j}+$ & $\mathbf{a}, \mathbf{b}, \mathbf{c}, \mathbf{d}, \mathbf{e}, \mathbf{f}$ \\
\hline Context B & e+, f-, g+, h- & $\mathbf{a}-, \mathbf{b}-, k+, l+$ & $\mathbf{a}, \mathbf{b}, \mathbf{c}, \mathbf{d}, \mathbf{e}, \mathbf{f}$ \\
\hline Trials per stimulus & & 8 & 4 \\
\hline \multicolumn{4}{|l|}{ (b) } \\
\hline Stimuli $a$ and $b$ & Context A & Context B & Context $A+B$ \\
\hline Stimuli $\mathrm{c}$ and $\mathrm{d}$ & Context A & Context A & Context $A+B$ \\
\hline Stimuli e and $f$ & Context B & Not shown & Context A+B \\
\hline
\end{tabular}

(a) Letters a-I represent different food stimuli presented during acquisition, extinction, and recall; symbols indicate the feedback given to the participant ( + causes stomach trouble, - does not cause stomach trouble; feedback was omitted during recall). The critical stimuli a, $c$, and e as well as the corresponding control stimuli $b, d$, and $f$ are highlighted in bold. (b) To test for $A B(A B)$ renewal, stimuli $a+$ and $b-$ were presented in context $A$ during acquisition, in context $B$ during extinction, and in context $A$ and context $B$ during recall. Stimuli $c+$ and $d-$ were presented in context $A$ during acquisition and extinction as well as in context $A$ and context $B$ during recall. Stimuli $e+$ and $f-$ (only shown in context $B$ during acquisition) served as no extinction control stimuli, they were presented during recall in context $A$ and contrasted with context $B$. 
Table 2. Allocation to the groups

\begin{tabular}{llll}
\hline & \multicolumn{1}{c}{ Day $\mathbf{1}$} & Day $\mathbf{2}$ & Day $\mathbf{3}$ \\
\hline Immediate extinction (early recall) & Acquisition, extinction & Recall & Recall \\
Immediate extinction (late recall) & Acquisition, extinction & Acquisition & Extinction \\
Delayed extinction & Recall \\
\hline
\end{tabular}

After immediate extinction, recall took place either $24 \mathrm{~h}$ later or $48 \mathrm{~h}$ later. In the delayed extinction group, extinction was scheduled $24 \mathrm{~h}$ after acquisition and $24 \mathrm{~h}$ before recall.

\section{Statistics}

Statistical analyses were conducted using IBM SPSS 20 Statistics for Windows with the significance level of $\alpha=0.05$. GreenhouseGeisser-corrected $P$-values were reported for repeated-measures analyses of variance (ANOVA) if the assumption of sphericity was not given. The factor group (immediate extinction (early recall) versus immediate extinction (late recall) versus delayed extinction) was always included as between-subject factor. In order to capture the variance related to potential sex differences, the factor sex (men versus women) was additionally inserted as a factor of no interest.

Analyses of systolic and diastolic blood pressure were conducted separately for each measure and for each experimental phase. To this end, the repeated measurement factor time was included (pre- versus post-acquisition; pre- versus post-extinction; pre- versus post-recall).

Behavioral performance in the predictive learning task was calculated as the mean percentage of stomach trouble predictions per stimulus and context across blocks of two trials for acquisition and extinction as well as across all trials for recall. For acquisition, a repeated-measures ANOVA was conducted with the within-subject factors stimulus (causing stomach trouble $(+)$ or not $(-)$ ), block (first versus second versus third versus fourth), and stimulus pair (a/b versus $\mathrm{c} / \mathrm{d}$ versus $\mathrm{e} / \mathrm{f})$. For extinction, the factors stimulus, block and context (A versus B) were entered. For recall, separate ANOVA for the critical stimulus pairs $\mathrm{a} / \mathrm{b}, \mathrm{c} / \mathrm{d}$, and $\mathrm{e} / \mathrm{f}$ (each undergoing different contingency and/or context changes during extinction; see section "Predictive learning task") were conducted with the within-subject factors stimulus and context.

\section{Competing interest statement}

All authors declare that they have no conflicts of interest.

\section{Acknowledgments}

We gratefully acknowledge the help of Sarah Chwalek, Andreas Haltermann, and Celine Schulte during data collection and recruitment of participants. Moreover, we thank Tobias Otto for technical support and Dr. Metin Uengoer for helpful comments on a first draft of this manuscript. This work was supported by Project A09 (C.J.M., O.T.W.) of the Collaborative Research Center 1280 "Extinction Learning," funded by the German Research Foundation (DFG). The DFG had no role in study design, collection, analysis and interpretation of data, writing of the manuscript, or in the decision to submit the paper for publication.

\section{References}

Alvarez RP, Johnson L, Grillon C. 2007. Contextual-specificity of short-delay extinction in humans: renewal of fear-potentiated startle in a virtual environment. Learn Mem 14: 247-253. doi:10.1101/lm.493707

Archbold GE, Bouton ME, Nader K. 2010. Evidence for the persistence of contextual fear memories following immediate extinction. Eur J Neurosci 31: 1303-1311. doi:10.1111/j.1460-9568.2010.07161.x

Arnsten AF. 2009. Stress signalling pathways that impair prefrontal cortex structure and function. Nat Rev Neurosci 10: 410-422. doi:10.1038/ nrn2648

Bandarian Balooch S, Neumann DL. 2011. Effects of multiple contexts and context similarity on the renewal of extinguished conditioned behaviour in an ABA design with humans. Learn Motiv 42: 53-63. doi:10.1016/j.lmot.2010.08.008

Bouton ME. 2002. Context, ambiguity, and unlearning: sources of relapse after behavioral extinction. Biol Psychiatry 52: 976-986. doi:10.1016/ S0006-3223(02)01546-9

Bouton ME. 2004. Context and behavioral processes in extinction. Learn Mem 11: 485-494. doi:10.1101/lm.78804

Bouton ME, Todd TP. 2014. A fundamental role for context in instrumental learning and extinction. Behav Processes 104: 13-19. doi:10.1016/j. beproc.2014.02.012

Chang CH, Maren S. 2009. Early extinction after fear conditioning yields a context-independent and short-term suppression of conditional freezing in rats. Learn Mem 16: 62-68. doi:10.1101/lm.1085009

Chang CH, Maren S. 2011. Medial prefrontal cortex activation facilitates re-extinction of fear in rats. Learn Mem 18: 221-225. doi:10.1101/ $\operatorname{lm} .2070111$

Chang CH, Berke JD, Maren S. 2010. Single-unit activity in the medial prefrontal cortex during immediate and delayed extinction of fear in rats. PLoS One 5: e11971.

Devenport LD. 1998. Spontaneous recovery without interference: why remembering is adaptive. Anim Learn Behav 26: 172-181. doi:10.3758/ BF03199210

Dibbets P, Havermans R, Arntz A. 2008. All we need is a cue to remember: the effect of an extinction cue on renewal. Behav Res Ther 46: 1070-1077. doi:10.1016/j.brat.2008.05.007

Effting M, Kindt M. 2007. Contextual control of human fear associations in a renewal paradigm. Behav Res Ther 45: 2002-2018. doi:10.1016/j. brat.2007.02.011

Giustino TF, Maren S. 2015. The role of the medial prefrontal cortex in the conditioning and extinction of fear. Front Behav Neurosci 9: 298.

Giustino TF, Seemann JR, Acca GM, Goode TD, Fitzgerald PJ, Maren S. 2017. $\beta$-adrenoceptor blockade in the basolateral amygdala, but not the medial prefrontal cortex, rescues the immediate extinction deficit. Neuropsychopharmacology 42: 2537-2544. doi:10.1038/npp.2017.89

Golkar A, Öhman A. 2012. Fear extinction in humans: effects of acquisition-extinction delay and masked stimulus presentations. Biol Psychol 91: 292-301. doi:10.1016/j.biopsycho.2012.07.007

Hamacher-Dang TC, Engler H, Schedlowski M, Wolf OT. 2013a. Stress enhances the consolidation of extinction memory in a predictive learning task. Front Behav Neurosci 7: 108.

Hamacher-Dang TC, Uengoer M, Wolf OT. 2013b. Stress impairs retrieval of extinguished and unextinguished associations in a predictive learning task. Neurobiol Learn Mem 104: 1-8. doi:10.1016/j.nlm.2013.04.007

Hamm AO, Vaitl D. 1996. Affective learning: awareness and aversion. Psychophysiology 33: 698-710. doi:10.1111/j.1469-8986.1996. tb02366.x

Hollis F, Sevelinges Y, Grosse J, Zanoletti O, Sandi C. 2016. Involvement of $\mathrm{CRFR}_{\mathbf{1}}$ in the basolateral amygdala in the immediate fear extinction deficit. eNeuro 3: ENEURO.0084-16.2016. doi:10.1523/ ENEURO.0084-16.2016

Holmes A, Wellman CL. 2009. Stress-induced prefrontal reorganization and executive dysfunction in rodents. Neurosci Biobehav Rev 33: 773-783. doi:10.1016/j.neubiorev.2008.11.005

Huff NC, Hernandez JA, Blanding NQ, LaBar KS. 2009. Delayed extinction attenuates conditioned fear renewal and spontaneous recovery in humans. Behav Neurosci 123: 834-843. doi:10.1037/a0016511

Johnson JS, Escobar M, Kimble WL. 2010. Long-term maintenance of immediate or delayed extinction is determined by the extinction-test interval. Learn Mem 17: 639-644. doi:10.1101/lm.1932310

Kaufman MA, Bolles RC. 1981. A nonassociative aspect of overshadowing. Bull Psychonomic Soc 18: 318-320. doi:10.3758/BF03333639

Kim JH, Richardson R. 2009. Expression of renewal is dependent on the extinction-test interval rather than the acquisition-extinction interval. Behav Neurosci 123: 641-649. doi:10.1037/a0015237

Kim SC, Jo YS, Kim IH, Kim H, Choi JS. 2010. Lack of medial prefrontal cortex activation underlies the immediate extinction deficit. J Neurosci 30: 832-837. doi:10.1523/JNEUROSCI.4145-09.2010 
Kinner VL, Merz CJ, Lissek S, Wolf OT. 2016. Cortisol disrupts the neural correlates of extinction recall. Neuroimage 133: 233-243. doi:10.1016/j. neuroimage.2016.03.005

Lissek S, Glaubitz B, Uengoer M, Tegenthoff M. 2013. Hippocampal activation during extinction learning predicts occurrence of the renewal effect in extinction recall. Neuroimage 81: 131-143. doi:10.1016/j. neuroimage.2013.05.025

MacPherson K, Whittle N, Camp M, Gunduz-Cinar O, Singewald N, Holmes A. 2013. Temporal factors in the extinction of fear in inbred mouse strains differing in extinction efficacy. Biol Mood Anxiety Disord 3: 13

Maren S. 2014. Nature and causes of the immediate extinction deficit: a brief review. Neurobiol Learn Mem 113: 19-24. doi:10.1016/j.nlm.2013. 10.012

Maren S, Chang CH. 2006. Recent fear is resistant to extinction. Proc Natl Acad Sci 103: 18020-18025. doi:10.1073/pnas.0608398103

Maren S, Holmes A. 2016. Stress and fear extinction. Neuropsychopharmacology 41: 58-79. doi:10.1038/npp.2015.180

Maren S, Phan KL, Liberzon I. 2013. The contextual brain: implications for fear conditioning, extinction and psychopathology. Nat Rev Neurosci 14: 417-428. doi:10.1038/nrn3492

Meir Drexler S, Hamacher-Dang TC, Wolf OT. 2017. Stress before extinction learning enhances and generalizes extinction memory in a predictive learning task. Neurobiol Learn Mem 141: 143-149. doi:10.1016/j. nlm.2017.04.002

Merz CJ, Hermann A, Stark R, Wolf OT. 2014. Cortisol modifies extinction learning of recently acquired fear in men. Soc Cogn Affect Neurosci 9: 1426-1434. doi:10.1093/scan/nst137

Merz CJ, Hamacher-Dang TC, Wolf OT. 2016. Immediate extinction promotes the return of fear. Neurobiol Learn Mem 131: 109-116. doi:10.1016/j.nlm.2016.03.013

Merz CJ, Hamacher-Dang TC, Stark R, Wolf OT, Hermann A. 2018. Neural underpinnings of cortisol effects on fear extinction. Neuropsychopharmacology 43: 384-392. doi:10.1038/npp.2017.227

Myers KM, Ressler KJ, Davis M. 2006. Different mechanisms of fear extinction dependent on length of time since fear acquisition. Learn Mem 13: 216-223. doi:10.1101/lm.119806

Neumann DL, Kitlertsirivatana E. 2010. Exposure to a novel context after extinction causes a renewal of extinguished conditioned responses: implications for the treatment of fear. Behav Res Ther 48: 565-570. doi:10.1016/j.brat.2010.03.002

Norrholm SD, Vervliet B, Jovanovic T, Boshoven W, Myers KM, Davis M, Rothbaum BO, Duncan EJ. 2008. Timing of extinction relative to acquisition: a parametric analysis of fear extinction in humans. Behav Neurosci 122: 1016-1030. doi:10.1037/a0012604

Pavlov IP. 1927. Conditioned reflexes. Oxford University Press, London.

Rescorla RA. 2004. Spontaneous recovery. Learn Mem 11: 501-509. doi:10.1101/lm.77504

Schiller D, Cain CK, Curley NG, Schwartz JS, Stern SA, LeDoux JE, Phelps EA. 2008. Evidence for recovery of fear following immediate extinction in rats and humans. Learn Mem 15: 394-402. doi:10.1101/lm.909208

Singh S, Siddiqui SA, Tripathy S, Kumar S, Saha S, Ugale R, Modi DR, Prakash A. 2018. Decreased level of histone acetylation in the infralimbic prefrontal cortex following immediate extinction may result in deficit of extinction memory. Brain Res Bull 140: 355-364. doi:10.1016/j.brainresbull.2018.06.004

Sjouwerman R, Niehaus J, Lonsdorf TB. 2015. Contextual change after fear acquisition affects conditioned responding and the time course of extinction learning - implications for renewal research. Front Behav Neurosci 9: 337.

Stafford JM, Maughan DK, Ilioi EC, Lattal KM. 2013. Exposure to a fearful context during periods of memory plasticity impairs extinction via hyperactivation of frontal-amygdalar circuits. Learn Mem 20: 156-163. doi:10.1101/lm.029801.112

Üngör M, Lachnit H. 2006. Contextual control in discrimination reversal learning. J Exp Psychol Anim Behav Process 32: 441-453. doi:10.1037/ 0097-7403.32.4.441

Üngör M, Lachnit H. 2008. Dissociations among ABA, ABC, and AAB recovery effects. Learn Motiv 39: 181-195. doi:10.1016/j.lmot. 2007.08.001

Vervliet B, Baeyens F, van den Bergh O, Hermans D. 2013a. Extinction, generalization, and return of fear: a critical review of renewal research in humans. Biol Psychol 92: 51-58. doi:10.1016/j.biopsycho.2012.01.006

Vervliet B, Craske MG, Hermans D. 2013b. Fear extinction and relapse: state of the art. Аnпu Rev Clin Psychol 9: 215-248. doi:10.1146/ annurev-clinpsy-050212-185542

Woods AM, Bouton ME. 2008. Immediate extinction causes a less durable loss of performance than delayed extinction following either fear or appetitive conditioning. Learn Mem 15: 909-920. doi:10.1101/lm. 1078508

Received August 27, 2018; accepted in revised form December 11, 2018. 


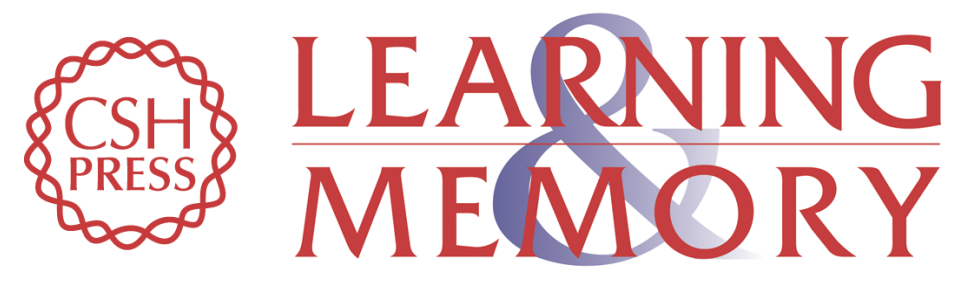

\section{The immediate extinction deficit occurs in a nonemotional learning paradigm}

Christian J. Merz and Oliver T. Wolf

Learn. Mem. 2019, 26:

Access the most recent version at doi:10.1101/Im.048223.118

\begin{aligned} & \hline References $\begin{array}{l}\text { This article cites } 50 \text { articles, } 13 \text { of which can be accessed free at: } \\ \text { http://learnmem.cshlp.org/content/26/2/39.full.html\#ref-list-1 }\end{array} \\ & \begin{array}{r}\text { Creative } \\ \text { Commons } \\ \text { License }\end{array} \begin{array}{l}\text { This article is distributed exclusively by Cold Spring Harbor Laboratory Press for the } \\ \text { first } 12 \text { months after the full-issue publication date (see } \\ \text { http://learnmem.cshlp.org/site/misc/terms.xhtml). After } 12 \text { months, it is available under } \\ \text { a Creative Commons License (Attribution-NonCommercial } 4.0 \text { International), as } \\ \text { described at http://creativecommons.org/licenses/by-nc/4.0/. }\end{array} \\ & \begin{array}{c}\text { Receive free email alerts when new articles cite this article - sign up in the box at the } \\ \text { top right corner of the article or click here. }\end{array} \\ & \begin{array}{l}\text { Service } \\ \text { terting }\end{array}\end{aligned}$

